\title{
ESTADO DE BIENESTAR Y OFERTA PROGRAMÁTICA EN ESPAÑA: UNA PROPUESTA METODOLÓGICA COMPARATIVA DE LOS PERFILES SOCIALES DE LOS PARTIDOS
}

\author{
Welfare State and party political programmes \\ in Spain: A comparative analysis \\ of parties' social profiles
}

\author{
CRISTINA ARES \\ Universidad de Santiago de Compostela \\ cristina.ares@usc.es \\ ANTÓN LOSADA \\ Universidad de Santiago de Compostela \\ antonio.losada@usc.es
}

Cómo citar/Citation

Ares, C. y Losada, A. (2019).

Estado de bienestar y oferta programática en España: una propuesta metodológica comparativa de los perfiles sociales de los partidos. Revista de Estudios Políticos, 184, 67-101. doi: https://doi.org/10.18042/cepc/rep.184.03

\section{Resumen}

Con la Gran Recesión iniciada en 2007, ha emergido en distintas sociedades europeas la preocupación por el tamaño del gasto social destinado a las personas mayores. En España, este debate se ha relacionado con la irrupción de Podemos y Ciudadanos. Presentamos una propuesta metodológica para definir en perspectiva comparada el perfil social y antisocial de los partidos políticos. Partimos de los programas «anotados» del Manifesto Corpus (Merz et al., 2016) y del modelo de pensamiento reaccionario propuesto por Hirschman (1991), sintetizado en la afirmación de que el Estado de bienestar (EdB) es «peligroso, inútil y perverso». Asimismo, empleamos datos del Manifesto Project para las 94 elecciones generales celebradas en la UE-15 desde 1993 e incluidas en la versión $2017 \mathrm{~b}$ de su base de datos principal (729 observaciones). Se analizan, al nivel meso de los partidos y al nivel macro de los Parlamentos nacionales, la posición sobre la 
extensión del gasto en políticas de bienestar y el énfasis en los recortes sociales. En España, se halla que Podemos y Ciudadanos no han ampliado la oferta de servicios para los jóvenes; sin embargo, estos partidos prestan escasa o nula atención a los mayores como destinatarios de atención social. Por su parte, ni el PP ni el PSOE han dado prioridad a las pensiones sobre otros programas de gasto, como la educación y el empleo. Aunque con poca intensidad, PP, UPyD y Ciudadanos han sido los únicos partidos en incluir recortes sociales en su oferta programática desde 1993. El PP ha ido variando la racionalidad de su discurso antisocial. En 2016, se ajustó a la idea de perversidad del EdB.

\section{Palabras clave}

Envejecimiento de la población; Estado de bienestar; Manifesto Corpus; Manifesto Project; gasto en políticas de bienestar; recortes sociales.

\section{Abstract}

Since the start of the Great Recession in 2007, increased concern has emerged about the amount of social expenditure devoted to the elderly in various European societies. In Spain, this debate has been linked to the irruption of two new political parties Podemos (We can) and Ciudadanos (Citizens). This paper presents a methodological proposal that aims to define, in comparative perspective, parties' social policy profiles. It is based on the annotated manifestos issued by the Manifesto Corpus (Merz et al., 2016) and on the Hirschman's conceptual model. The latter summarises critiques of the Welfare State (WS) in three arguments of perversity, futility, and jeopardy. Data from the Manifesto Project on the 94 general elections held in the EU-15 from 1993 onwards, and covered in the " $2017 \mathrm{~b}$ " version of its main dataset (729 observations), are used. Parties' positions on the expansion of welfare spending and emphases on social cuts are examined, both at the meso-level of political parties and the macro-level of national Parliaments. In Spain, Podemos and Ciudadanos have not offered to expand social services for the young generations and, moreover, they have paid scarce attention to the elderly. Neither the Partido Popular (PP, Popular Party), nor the Partido Socialista Obrero Español (PSOE, Socialist Party), have given greater priority to pensions in comparison to other welfare programmes, such as education or employment. Finally, since 1993, the PP, Ciudadanos and Unión Progreso y Democracia (UPyD, Union, Progress and Democracy) have been the only parties supportive of cuts to social spending, albeit infrequently. The PP has changed its reasons for proposing cuts to social spending over time. By 2016, these reasons were consistent with the idea of the perversity of the welfare state.

\section{Keywords}

Population Ageing; Welfare State; Manifesto Corpus; Manifesto Project; welfare spending; social retrenchment. 


\section{SUMARIO}

I. INTRODUCCIÓN. II. PRIMERA PARTE: PREFERENCIAS DE LOS PARTIDOS SOBRE LA EXTENSIÓN Y LA LIMITACIÓN DEL GASTO SOCIAL: 1. Índices de posición sobre la extensión del gasto social y el énfasis en los recortes. 2. Preferencias de los parlamentos nacionales de la UE-15 sobre gasto social. III. SEGUNDA PARTE: PERFILES SOCIALES DE LOS PARTIDOS EN FUNCIÓN DE LOS BENEFICIARIOS Y LOS PROGRAMAS DE GASTO PRIORIZADOS: 1. Contra el Estado de Bienestar, por «peligroso, inútil y perverso». 2. ¿Cómo medir en perspectiva comparada el perfil social de los partidos?. 3. Los perfiles sociales de los principales partidos españoles de ámbito estatal. IV. CONCLUSIONES. Biblografía. Apéndice de tablas.

\section{INTRODUCCIÓN}

El Estado de bienestar (EdB) es uno de los principales rasgos característicos del sistema político de la Unión Europea (UE), creado por el Tratado de Maastricht en 1993. Sin embargo, incluso tras la Gran Recesión, las políticas sociales siguen siendo fundamentalmente competencia de los Estados. La narrativa más exitosa de la Unión presenta su lógica de la integración como un medio para dar continuidad al modelo social europeo (MSE) de crecimiento y bienestar en la globalización. El MSE se basa en los siguientes tres pilares: equidad, progresividad fiscal y eficiencia económica (Moreno, 2013).

Sin embargo, la idea "peligrosa» (Blyth, 2014) de austeridad, que ha protagonizado la vida política de la UE desde el inicio de la Gran Crisis, en 2007, ha restado credibilidad a este relato. De hecho, en algunos países, se ha extendido la creencia de que la integración dificulta el diseño e implementación de las políticas nacionales de bienestar.

Este artículo estudia las preferencias de los partidos políticos sobre el volumen y el reparto del gasto social. En concreto, por una parte, examina la posición de los partidos acerca de la extensión de la financiación de las políticas de bienestar y su énfasis en los recortes y, por otra, sus prioridades con relación a los grupos beneficiarios de atención social y los diferentes programas de gasto. El análisis se realiza no solo al nivel meso de los partidos, sino también al nivel macro de los Parlamentos nacionales de la UE-15 desde 1993. Se examinan 729 partidos con representación parlamentaria y 94 períodos legislativos. 
El ámbito territorial son los países que conformaron la UE-15 (Alemania, Austria, Bélgica, Dinamarca, España, Finlandia, Francia, Grecia, Irlanda, Italia, Luxemburgo, Países Bajos, Portugal, Reino Unido y Suecia), porque los Estados de la Unión incorporados con posterioridad, a partir de 2004, en su mayoría de Europa Oriental, presentan modelos de bienestar demasiado diferentes para incluirlos en esta comparación.

El texto se divide en dos grandes partes. La primera (epígrafes 2 y 3 ) contiene una breve nota metodológica sobre el cálculo de los índices de posición acerca de la extensión del gasto social y el énfasis en los recortes. Se analizan los Parlamentos de la UE-15 para identificar las singularidades de la diferenciación programática en materia de bienestar en Espańa que se estudia a continuación.

La segunda parte (epígrafes 4 a 6) presenta el desarrollo metodológico que, gracias a los programas «anotados» ofrecidos por el Manifesto Corpus (Merzet al., 2016), permite crear nuevos datos comparativos entre países y en el tiempo acerca de los perfiles sociales y antisociales de los partidos. Se introduce la base conceptual empleada para la medición de estos perfiles, que es el modelo de pensamiento reaccionario de Hirschman (1991). Se optó por este enfoque debido a su capacidad para integrar en las nociones generales de «peligrosidad», «inutilidad» y «perversidad» el conjunto de las críticas al EdB, incluidas las incorporadas a los conceptos de guerra entre generaciones y conflicto intergeneracional emergentes hoy en día en el debate público de algunas sociedades envejecidas (Ares, 2018). Finalmente, esta herramienta, perfilada inductivamente a partir del análisis de programas de distintos países y familias de partidos para el conjunto de la UE-15, se aplica en este artículo a los principales partidos españoles de ámbito estatal.

\section{PRIMERA PARTE: PREFERENCIAS DE LOS PARTIDOS SOBRE LA EXTENSIÓN Y LA LIMITACIÓN DEL GASTO SOCIAL}

\section{1. ÍNDICES DE POSICIÓN SOBRE LA EXTENSIÓN DEL GASTO SOCIAL Y EL ÉNFASIS EN LOS RECORTES}

Para el cálculo de las preferencias de los partidos y Parlamentos nacionales de la UE-15 empleamos la base de datos principal del proyecto Manifesto (Volkens et al., 2017). Optamos, de este modo, por datos elaborados a partir del análisis de contenido cuantitativo de programas electorales. Este se realiza a través de la codificación manual por parte de expertos en los distintos países, capaces de atribuir significado a los argumentos contenidos en las unidades de análisis, que son las cuasifrases, y no las palabras, porque las palabras no tienen 
significado fuera de contexto. Para profundizar sobre el método de este proyecto, pueden consultarse Alonso et al. (2012), Ares y Volkens (2017a, 2017b) y Volkens et al. (2013 y 2015).

En esta investigación tomamos las siguientes cuatro variables del esquema de clasificación estándar, porque son las que versan sobre gasto social:

- Extensión del Estado de bienestar (categoría 504). Referencias favorables a la necesidad de introducir, mantener o ampliar los servicios sociales públicos o el programa de seguridad social. Esto incluye, por ejemplo, la financiación gubernamental de asistencia sanitaria, asistencia a los ancianos y pensiones, atención infantil, o vivienda social.

- Extensión de la Educación (506). Necesidad de ampliar y/o mejorar la oferta educativa en todos los niveles. Excluye la formación técnica (categoría 411).

- Restricción del Estado de bienestar (505). Limitación de los gastos del Estado en servicios sociales o seguridad social. Referencias favorables al principio social subsidiario (es decir, una asistencia privada frente a una asistencia estatal).

- Restricción de la educación (507). Restricción del gasto estatal en educación. Puede incluir: la introducción o incremento de tasas en todos los niveles educativos, o el aumento del número de centros educativos privados.

Para el cálculo de la posición de cada uno de los 729 partidos sobre la extensión del gasto social, aplicamos la siguiente fórmula: $(504+506)-(505$ + 507). En el nivel macro, para la obtención de la posición del Parlamento nacional en cada legislatura, ponderamos las preferencias de los partidos con representación en el período por su número de escaños.

El índice de énfasis en los recortes sociales es el resultado de sumar las dos categorías que capturan los posicionamientos favorables a la limitación del gasto social $(505+507)$. A nivel macro, se realiza la misma ponderación que para el anterior índice de posición sobre la expansión del volumen de recursos destinado a las políticas de bienestar en cada uno de los 94 períodos legislativos cubiertos.

\section{PREFERENCIAS DE LOS PARLAMENTOS NACIONALES DE LA UE-15 SOBRE GASTO SOCIAL}

Este epígrafe ofrece una aproximación al espacio real de diferenciación de la oferta sobre las políticas sociales en la UE-15, que nos permite desmentir algunas falsas creencias presentes en la conversación acerca del EdB. Los 
gráficos 1 y 2 ilustran una enorme cantidad de información, fruto del cálculo de los dos índices anteriormente presentados para los 729 partidos y las 94 elecciones celebradas en estos países entre 1993 y 2017 y codificadas por el Manifesto Project a finales de 2017.

En el primero, se observa nítidamente cómo el apoyo al incremento del gasto social creció hasta el año 2000, cuando se estancó, y cómo se desplomó después en los primeros años de la Gran Crisis.

\section{Gráfico 1. Posición sobre la extensión del gasto social}

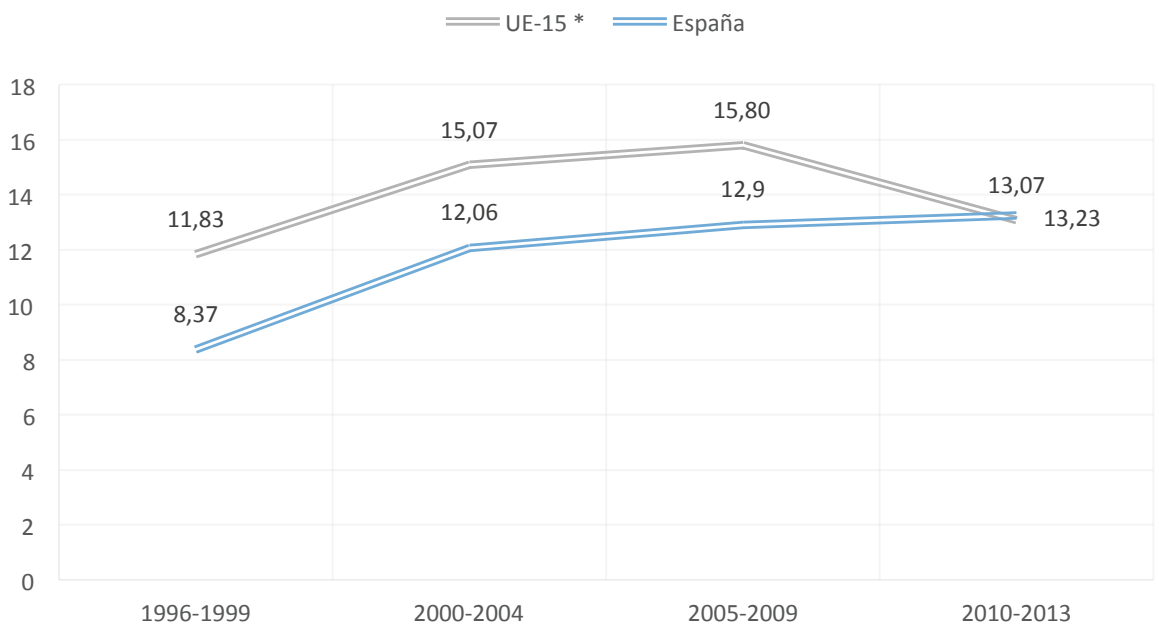

* La posición de la UE-15 sobre la extensión del gasto social es la posición media de los Parlamentos nacionales de Alemania, Austria, Bélgica, Dinamarca, España, Finlandia, Francia, Grecia, Irlanda, Italia, Luxemburgo, Países Bajos, Portugal, Reino Unido y Suecia. Para su cálculo, en cada período legislativo, primero, se obtuvo la posición de cada partido con representación parlamentaria, aplicando la fórmula $(504+506)-(505+507)$; a continuación, se ponderó por su número de escaños. El último año es 2013 porque no se dispone todavía de datos comparables correspondientes al siguiente ciclo electoral para los quince países.

Fuente: elaboración propia con datos del Manifesto Project, versión 2017b.

Llama la atención el consistente mantenimiento a lo largo del tiempo de las preferencias del Congreso de los Diputados en torno a tres puntos por debajo de la media de los Parlamentos de la UE-15. Sin embargo, en 2011 el Parlamento español se ubica inusualmente en la posición media y las líneas se cruzan. 
El gráfico 2, por su parte, refleja la escasa presencia de posicionamientos programáticos favorables a la limitación del gasto social. Cuando en el conjunto de la UE-15 se incluyeron más argumentos a favor de los recortes, en el ciclo electoral de 2011, durante los momentos más duros de la Gran Recesión, no llegaron a sobrepasar el 1,02 de la oferta. Este limitado énfasis es característico de los quince países, y en mayor medida de España, que solo se aproxima a la media de la UE-15 en los años 2000.

\section{Gráfico 2. Énfasis en los recortes sociales}
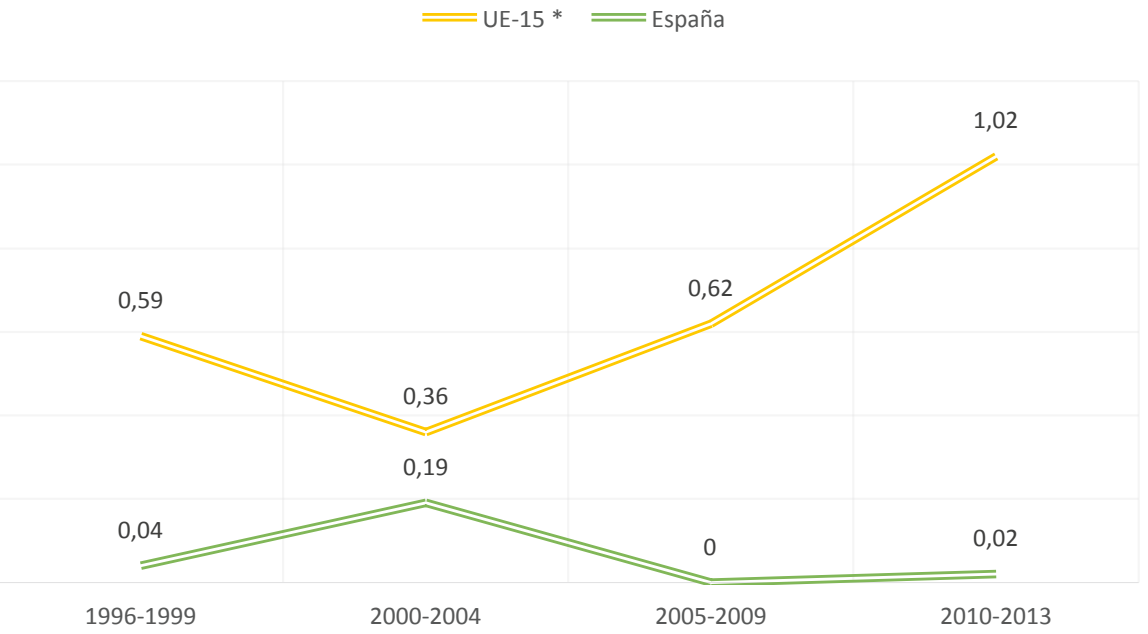

* El énfasis de la UE-15 acerca de los recortes sociales es la preferencia media de los Parlamentos nacionales de Alemania, Austria, Bélgica, Dinamarca, España, Finlandia, Francia, Grecia, Irlanda, Italia, Luxemburgo, Países Bajos, Portugal, Reino Unido y Suecia. Para el cálculo, en cada período legislativo, primero, se obtuvo la puntuación de cada partido con representación parlamentaria, aplicando la fórmula $(505+507)$; a continuación, se ponderó por su número de escaños. El último año es 2013 porque no se dispone de datos comparables posteriores para los quince países.

Fuente: elaboración propia con datos del Manifesto Project, versión $2017 \mathrm{~b}$.

El gráfico 3 muestra el limitado énfasis o la irrelevancia en el nivel macro de los Parlamentos nacionales de los posicionamientos favorables a los recortes sociales en los quince Estados. En este ciclo electoral ningún país presentó un dato de énfasis en la reducción de los programas de gasto por encima del 2,33 de Portugal, donde todavía así se mantuvo el apoyo al incremento de la 
financiación de las políticas de bienestar $(11,3)$ unas décimas por encima de Alemania $(11,17)$.

\section{Gráfico 3. Énfasis en los recortes sociales (2010-2013)}

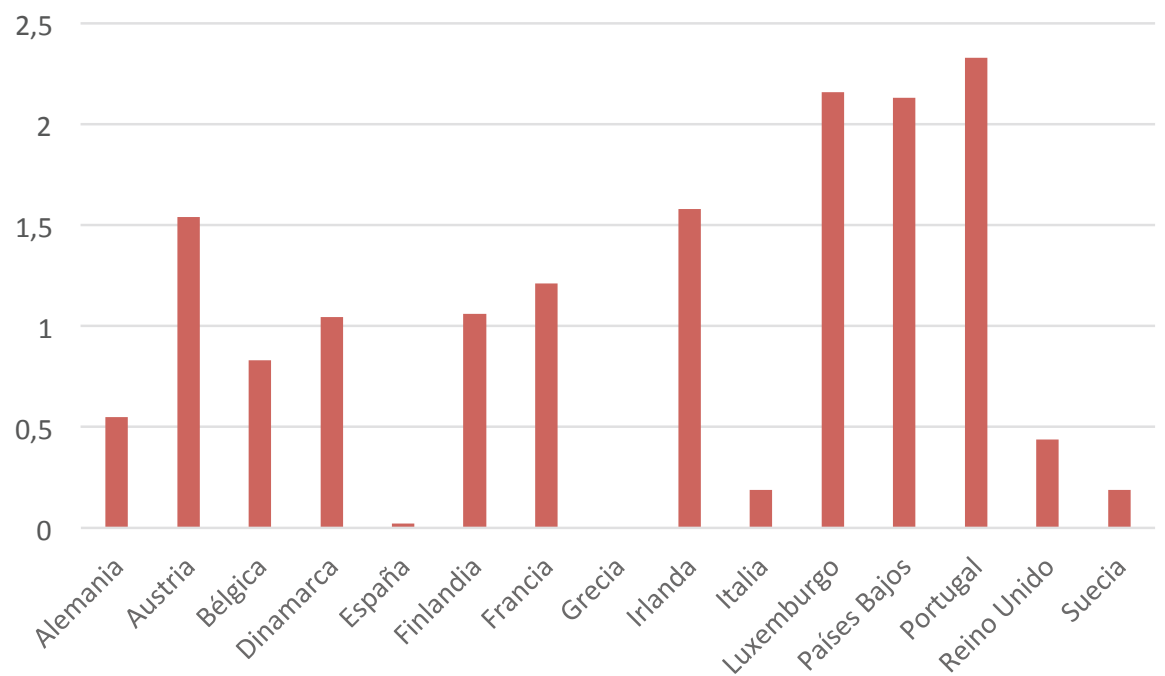

Fuente: elaboración propia con datos del Manifesto Project, versión 2017b.

En este mismo gráfico salta a la vista cómo en España $(0,02)$, al igual que en Grecia (0), los principales partidos evitaron estratégicamente las referencias a los recortes sociales en sus ofertas electorales.

Todos los datos anteriores contrastan con la sobrerrepresentación de posicionamientos antisociales en el debate público sobre el EdB, aspecto sobre el que abundaremos más adelante. Tras esta visión panorámica podemos afirmar que, en general, los ciudadanos de la UE-15 no votan a partidos antisociales y los partidos procuran no distanciarse del consenso a favor del MSE.

No obstante, una cosa es que no aumente el énfasis en los recortes y otra, como se ha mostrado en el gráfico 1, que se mantengan los posicionamientos favorables a la extensión de los programas de gasto. De hecho, estos caen para el conjunto de la UE-15 desde 2008.

En la comparación entre países destacan los Estados con movimientos en dirección contraria a la tendencia general, entre ellos Espańa. El país donde más se fortalece el apoyo al aumento de la financiación para estas políticas en el Parlamento es Alemania (5,81 puntos), seguido de Dinamarca (5,16 
puntos) y, en menor medida, Austria $(2,73)$, Suecia $(2,11)$ y Portugal $(0,62)$, además de España (1,21 puntos).

Mientras, se desplazaron en sentido contrario, como la media de la UE-15, las posiciones sobre la extensión de los programas de gasto de los Parlamentos (de mayor a menor variación): griego $(-12,06)$, irlandés $(-7,38)$, holandés $(-6,16)$, finlandés $(-6,05)$, británico $(-5,46)$, luxemburgués $(-5,27)$, belga $(-3,46)$, francés $(-1,71)$ e italiano $(-0,73)$. Todos estos movimientos se recogen en la tabla 2 del anexo.

Para poder interpretar estas variaciones, es preciso compararlas con las preferencias de las elecciones anteriores. En algunos países eran y, pese a su caída a partir de 2007, continuaron siendo favorables al crecimiento del EdB. Por ejemplo, en Francia el apoyo al aumento del gasto social descendió 1,71 puntos, pero no por ello, como se refleja en el gráfico 3, el galo dejó de ser el segundo Estado de la UE-15, solo por debajo de Suecia $(26,49)$, con una posición más favorable a una mayor dotación presupuestaria para las políticas de bienestar $(17,72)$. En la tabla 3 del anexo pueden consultarse no ya los cambios producidos durante la Gran Crisis (contenidos en la tabla anterior), sino las puntuaciones sobre la extensión del gasto de los quince Parlamentos nacionales en el ciclo electoral 2010-2013.

Gráfico 4. Posición sobre la extensión del gasto social (2010-2013)

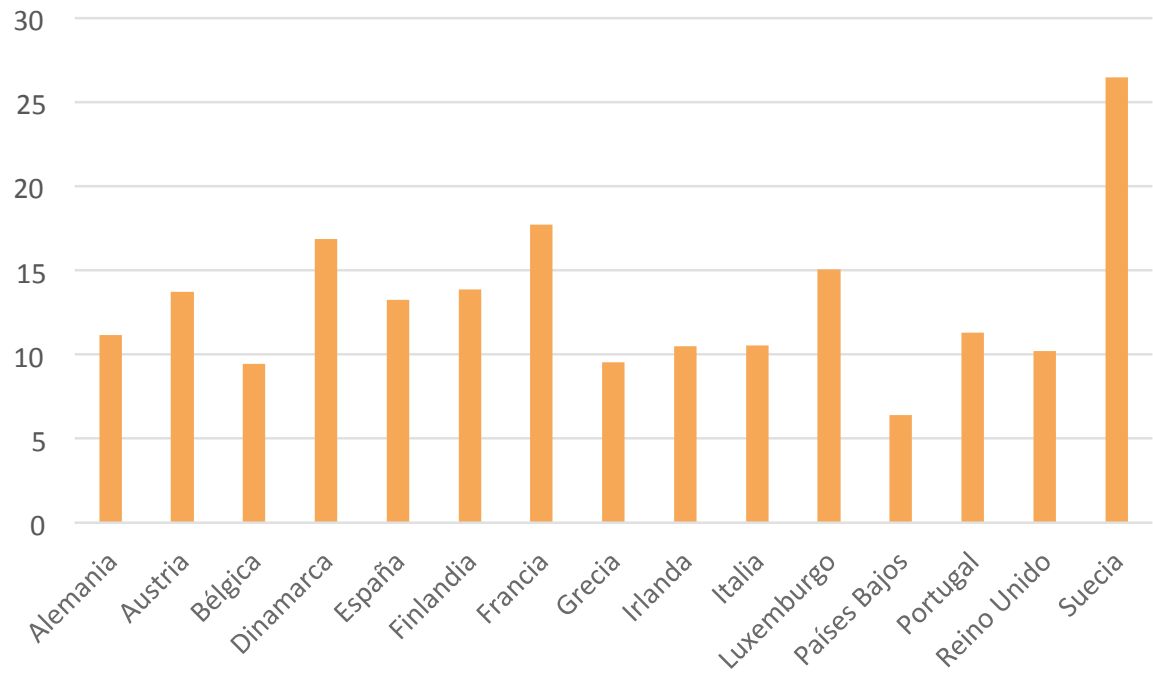

Fuente: elaboración propia con datos del Manifesto Project, versión 2017b. 
Tabla 1. Máximo énfasis en los recortes sociales desde 1993

\begin{tabular}{lccllcc}
\hline \multicolumn{1}{c}{ País } & Ańo & $\begin{array}{c}\text { Máximo énfasis en } \\
\text { los recortes sociales }\end{array}$ & \multicolumn{1}{c}{ Partido* } & Familia & RILE** & $\begin{array}{c}\% \\
\text { votos }\end{array}$ \\
\hline Portugal & 2011 & 10,7 & CDS-PP & CR & 22,82 & 12,21 \\
\hline Finlandia & 1995 & 9,76 & SK & AGRA & 26,83 & 19,85 \\
\hline Luxemburgo & 1994 & 7,87 & DP/PD & LIB & 15,16 & 19,3 \\
\hline Países Bajos & 1994 & 7,35 & RPF & CR & 12,63 & 1,8 \\
\hline Italia & 2008 & 6,98 & IdV & LIB & 9,3 & 4,36 \\
\hline Bélgica & 2003 & 6,59 & MR & LIB & $-29,64$ & 11,4 \\
\hline Dinamarca & 2011 & 4,93 & KF & CON & 20,37 & 4,92 \\
\hline Alemania & 1998 & 4,68 & FDP & LIB & 14,74 & 6,25 \\
\hline Austria & 2013 & 4,35 & FPÖ & NACIO & 12,17 & 20,51 \\
\hline Francia & 1993 & 3,64 & UDF & CON & 10,91 & 19,632 \\
\hline Suecia & 2014 & 3,42 & CP & CR & 7,9 & 6,11 \\
\hline Irlanda & 2011 & 2,73 & Fine Gael & CR & 0,73 & 36,1 \\
\hline Reino Unido & 2005 & 2,03 & Conservatives & CON & 14,54 & 32,36 \\
\hline Grecia & 2015 & 0,93 & To Potami & SCDM & $-12,92$ & 5,91 \\
\hline Espańa & 2000 & 0,68 & PP & CON & 3,59 & 44,52 \\
\hline
\end{tabular}

* Acrónimos: CDS-PP (Centro Socialdemócrata-Partido Popular), SK (Centro Finés), DP/PD (Partido Democrático), RPF (Federación Política Reformadora), IdV (Lista Di Pietro-Italia de los Valores), MR (Movimiento Reformador), KF (Partido Popular Conservador), FDP (Partido Libre Democrático), FPÖ (Partido de la Libertad), UDF (Unión para la Democracia Francesa), CP (Partido del Centro), PP (Partido Popular).

** RILE es un índice multidimensional ofrecido por el proyecto Manifesto. Integra variables económicas, sociales y culturales, entre otras, para medir el posicionamiento de los partidos en la dimensión izquierda-derecha. Se calcula con veintiséis categorías del esquema de clasificación estándar (códigos entre paréntesis), aplicando la siguiente fórmula: derecha [Ejército: positivo (104) + Libertad y derechos humanos (201) + Constitucionalismo: positivo (203) + Autoridad política (305) + Economía de libre mercado (401) + Incentivos (402) + Proteccionismo: negativo (407) + Ortodoxia económica (414) + Limitación del Estado de bienestar (505) + Forma de vida nacional: positivo (601) + Moralidad tradicional: positivo (603) + Ley y orden público (605) + Armonía social (606)] - [Antiimperialismo (103) + Ejército: negativo (105) + Paz (106) + Internacionalismo: positivo (107) + Democracia (202) + Regulación del mercado (403) + Planificación económica (404) + Proteccionismo: positivo (406) + Economía controlada (412) + Nacionalización (413) + Expansión del Estado de bienestar (504) + Expansión de la educación (506) + Grupos laborales: positivo (701)]. Debido a que este índice está construido para la comparación extensa entre países y en el tiempo, los veintiséis indicadores tienen el mismo peso. En teoría, la puntuación puede oscilar entre -100 (programa compuesto únicamente por posicionamientos de izquierda) y +100 (programa dedicado en exclusiva a ideas de derecha). Para más información, veáse: Volkens et al. (2013) y Ares y Volkens (2017a).

Fuente: elaboración propia con datos del Manifesto Project, versión $2017 \mathrm{~b}$. 
En definitiva, sería erróneo o intelectualmente deshonesto diagnosticar un deterioro dramático del apoyo programático a la extensión del gasto social en la UE-15 a nivel macro. No obstante, cabe apuntar algunas excepciones. En los País Bajos cayó 6,16 puntos, situándose en 6,38. Los rescates a Grecia $(-12,06)$ e Irlanda $(-7,38)$ tuvieron asimismo un impacto negativo en la defensa de la ampliación de los programas de gasto. En Finlandia el sostén al incremento de la financiación de las políticas de bienestar descendió 6,05 puntos, aunque continuó siendo el quinto más alto de los países estudiados.

Para terminar esta sección, se apuntan los datos desviados a nivel meso sobre el énfasis en los recortes sociales. La tabla 1 concentra información diversa valiosa para monitorizar las estrategias de oposición al EdB en la UE-15 desde 1993.

En primer lugar, el mayor énfasis en los recortes no siempre se produjo tras la Gran Crisis (lo que ocurrió en siete de los quince Estados), sino que en cinco de ellos (Alemania, Finlandia, Francia, Luxemburgo y Países Bajos) se había manifestado en la década de 1990 y en tres (Bélgica, España y el Reino Unido) en los primeros años 2000.

En segundo lugar, la puntuación más crítica es inferior a tres puntos no solo en España, sino también en Grecia, Irlanda y el Reino Unido. Tampoco alcanza los cinco puntos en ningún partido en ninguna elección desde el año 1993 en Alemania, Austria, Dinamarca, Francia y Suecia.

Entre estos nueve países solo cabría destacar dos, debido al respaldo electoral de la fuerza política que presentó la posición más antisocial. Se trata de la Unión para la Democracia Francesa (UDF), partido conservador que obtuvo en 1993 el 19,63\% de los sufragios, con el 3,46\% de su programa dedicado a los recortes; y el Partido de la Libertad (FPÖ), fuerza nacionalista con una ubicación en la escala izquierda-derecha muy próxima a la anterior, que logró en Austria el 20,51\% de los votos en 2013.

Por tanto, los tres países del Benelux, Finlandia, Italia y Portugal son contextos donde profundizar en el análisis de la contestación a los programas de gasto a nivel meso. En estos seis Estados, sí han existido partidos, agrarios, cristianodemócratas y liberales, que en algún momento han competido electoralmente dando mayor importancia a la reducción del gasto social y obteniendo apoyos de entre el 10 y el $20 \%$ de los votantes.

En la segunda parte de este texto se presenta la nueva propuesta metodológica para obtener más datos comparables relevantes sobre la diferenciación de la oferta en materia de bienestar y se aplica a los principales partidos españoles de ámbito estatal. 


\section{SEGUNDA PARTE: PERFILES SOCIALES DE LOS PARTIDOS EN FUNCIÓN DE LOS BENEFICIARIOS Y LOS PROGRAMAS DE GASTO PRIORIZADOS}

\section{CONTRA EL ESTADO DE BIENESTAR, POR «PELIGROSO, INÚTIL Y PERVERSO»}

Primero, exponemos la base conceptual sobre la que se construye esta herramienta de medición.

Tiempo antes de la Gran Crisis, durante las décadas de 1980 y 1990, el exitoso cuestionamiento del papel del Estado como actor económico y del valor de la intervención pública había marcado el debate en materia de política económica. La idea de EdB enfrentó críticas que ponían en cuestión su viabilidad económica (O'Connor, 1973, 1984; Esping-Andersen, 1990; Pierson, 1991; Boix 1996; Esping-Andersen y Parlier, 2010), su legitimidad política o moral (Niskanen, 1971; Nozick, 1974), la valoración social de su efectividad o su propia capacidad organizativa o tecnológica para intervenir en la economía o en la sociedad con eficiencia y eficacia (Offe, 1985; Cutler y Wayne, 1994; Lane y Ersson, 1999).

Más que en promover recortes significativos y visibles en sus volúmenes presupuestarios, las críticas contra el EdB se concentraron en cuestionar su legitimidad, su eficiencia o la moralidad de las maneras de gestionar el gasto (Scharpf, 1991, 1999a, 1999b; Pinch, 1997). Más que confrontar directamente al EdB, se pretendió reformular el propio concepto poniendo en circulación fórmulas que, bajo el paraguas de buscar una gestión más «neutral»o «gerencial», centraban sus esfuerzos en convertir las decisiones sobre elaboración de políticas o formas de gestión no en elecciones políticas, sino en decisiones racionales esencialmente técnicas. Así nació el «Estado gerencial» (Clarke y Newman, 1999), que ha orientado programáticamente la mayor parte de las reformas implementadas en las políticas de bienestar.

Sin embargo, la Gran Crisis ha facilitado recrear un escenario diferente y unos objetivos de mayor calado. No se trata ya de reformar, revisar o ajustar, sino de deteriorar, descapitalizar y, finalmente, desmantelar los servicios públicos y, en última instancia, el propio concepto, la idea de EdB (Losada, 2013). Esta nueva lógica reaccionaria contra los programas de gasto se descifra con mayor claridad si se sistematiza aplicando el modelo del pensamiento reaccionario formulado por Hirschmann (1991). Todo intento de progreso provoca una reacción armada con una batería de argumentos que, tras su habitualmente abundante despliegue moralizante y estadístico, puede reducirse a los siguientes tres conceptos: peligrosidad (jeopardy), inutilidad (futility) y perversidad (perversity). El empeño en el cambio o resulta peligroso o inútil o perverso: 
El Estado del bienestar es peligroso. La crítica más popular al EdB apunta a su insostenibilidad económica y al consiguiente riesgo que supone para otros avances económicos y sociales, sobre todo para la creación de riqueza y bienestar. El EdB ha sido declarado culpable del déficit y los desequilibrios del presupuesto público que, pese a la evidencia de los verdaderos orígenes y causas de la crisis financiera de 2007, acaban siendo presentados como el principal condicionante de la recesión. En este relato no fue la voracidad de los mercados financieros para especular con productos tóxicos lo que provocó la Gran Crisis, sino los elevados costes de la sanidad o de los sistemas de pensiones.

El Estado del bienestar es inútil. La regulación pública del mercado de trabajo con mecanismos como el salario mínimo lleva décadas bajo la sospecha de ineficiencia. En la era de los mercados globalizados esta sospecha se ha convertido en certeza. La intervención pública en la economía para regular los mercados laborales o de servicios resulta inútil. El caso de las políticas fiscales se ha convertido en el paradigma de la inutilidad del EdB. Subir los impuestos para financiar políticas de bienestar no solo causa un daño económico y amenaza la creación de riqueza; además resulta inútil porque aquellos con más capacidad fiscal disponen hoy de una movilidad casi ilimitada.

El Estado del bienestar es perverso. El exceso de protección social y el recurso confiscatorio a políticas redistributivas están aniquilando el espíritu emprendedor. El EdB genera una cultura de la subvención y la dependencia que desincentiva la iniciativa individual y daña el progreso económico. Con abundante apoyo de sofismas y formatos seudocientíficos se ha elaborado un poderoso discurso donde el gasto social no responde a las necesidades de los ciudadanos, sino a los intereses particulares de los «burócratas» y "políticos», que deciden y gestionan en su propio interés y fuera del control de los ciudadanos (Dunleavy, 1991). Así, el EdB se retrata como una amenaza para la libertad individual.

Finalmente, gana protagonismo el argumento de la insostenibilidad del gasto social en sociedades envejecidas, como las europeas. En realidad, se trata de una crítica antigua. La idea de que las democracias del bienestar degenerarían en gerontocracia fue puesta en circulación en la década de 1970 desde ámbitos de pensamiento conservador norteamericano. Sin embargo, ni las evidencias ni los análisis comparados suministraron base para fundamentar la idea de que un creciente poder de las personas de más edad estaba capturando el EdB y sus políticas en beneficio de los intereses de las personas mayores.

Los estudios comparados disponibles no arrojan evidencia alguna que permita sustentar la expectativa de que conforme aumenta el peso demográfico de los mayores se incremente su influencia en las decisiones públicas, voten como un grupo o lleguen a organizarse políticamente como tales para defender sus intereses (Lynch, 2015; Schulzt y Binstock, 2006). En realidad, 
la expansión de políticas como las pensiones responde a preferencias mayoritarias entre los trabajadores en activo, empresarios, activistas sociales, sindicatos y partidos de gobierno (Lynch, 2015).

Igualmente ha quedado acreditado que las sociedades del bienestar con políticas más favorables hacia las personas mayores, incluso con elevadas ratios de dependencia, reducen la probabilidad de que estos se activen para participar en política con intención de controlar la toma de decisiones públicas (Goerres, 2009). Las evidencias disponibles resultan contundentes: no se constatan ni se intuyen signos de la pronosticada gerontocracia (Ares, 2018). En lugar de intereses comunes que organicen o movilicen a la mayoría de las personas mayores como activistas o votantes, se observan preferencias diversas entre mayores y distintos grados de militancia y participación, como ocurre en otros grupos y cohortes de edad (Busemeyer et al., 2008; Goerres, 2007, 2009).

La Gran Recesión ha revivido, sin embargo, este falso concepto de gerontocracia y la pretensión de ruptura del contrato intergeneracional en el debate mediático. Ignorando la evidencia de que las reformas laborales implementadas en Europa han tenido como objetivo prioritario abaratar el recambio de trabajadores séniores - con trabajos estables y con condiciones previas a la crisis- por jóvenes más precarizados para reducir costes laborales; que los recortes en sanidad han afectado mayoritariamente a sus principales usuarios, las personas mayores, o que las pensiones o han sufrido recortes o no han dejado de perder poder adquisitivo desde 2008, se ha relanzado la idea de que las políticas de austeridad impuestas por algunos Gobiernos como salida a la crisis venían dictadas por la presión de los votantes más envejecidos para preservar sus derechos a costa de las oportunidades de las nuevas generaciones.

La idea de ruptura de contrato intergeneracional y guerra entre generaciones responde a la perfección a la producción del pensamiento reaccionario contra el EdB en conjunto. Desarrolla además la misma lógica populista de enfrentamiento y desconfianza que pretende explicar la crisis como el resultado de la explotación de la ciudadanía por ciertos grupos privilegiados y ha buscado enfrentar a nacionales contra inmigrantes aprovechados y abusivos, a empleados contra parados subsidiados que no querían trabajar o a ciudadanos contra funcionarios privilegiados.

El Estado del bienestar es aún más peligroso en las sociedades envejecidas porque el crecimiento constante de los costes asociados al mantenimiento de las políticas y servicios que más benefician a las personas mayores, como las pensiones o la sanidad, se ha convertido en la principal amenaza para la sostenibilidad de los sistemas del bienestar y las pensiones que esperan recibir en el futuro los trabajadores en activo. Además, esta amenaza tiene un carácter doble dado que tales políticas y servicios, siempre presentadas como un gasto 
escasamente productivo, han obligado a implementar recortes precisamente en aquellas medidas destinadas a otros grupos de edad más productivos y que resultan críticas para la creación de la riqueza, el crecimiento económico y el empleo que deben financiar el bienestar del futuro.

Las pensiones se presentan como una carga que deben soportar los trabajadores en activo en un escenario predictivo donde las ratios de dependencia no dejan de medrar amenazando con colapsar no solo al sistema de bienestar, sino el conjunto de la actividad económica y por tanto el crecimiento y la creación de riqueza. Las pensiones dejan de tratarse como un derecho y se convierten en un problema económico y financiero que debe resolverse.

El Estado del bienestar es aún más inútil porque el coste creciente de mantener un sistema público de pensiones resulta insostenible de forma inevitable. Las reformas sucesivas y los alarmantes modelos predictivos respecto a los programas de pensiones insisten de manera recurrente en la misma idea: los sistemas públicos no tienen futuro y resulta ineludible su complementación o su sustitución por sistemas privados. Consumir un volumen excesivo de recursos para preservarlos se antoja un esfuerzo fútil con un coste de oportunidad inasumible frente a otras políticas y servicios que sí pueden generar riqueza y bienestar.

El Estado del bienestar es aún más perverso porque mantener los derechos y servicios que benefician a los ciudadanos séniores se hace a costa de recortar las oportunidades a disposición de las generaciones más jóvenes. El discurso recurrente para justificar las sucesivas reformas laborales que han conducido al deterioro y desmantelamiento de las condiciones de los trabajadores ha girado en torno a una misma idea: se protege demasiado a los trabajadores indefinidos y mayores y eso impide o retrasa el acceso al empleo de los jóvenes.

\section{2. ¿̇CÓMO MEDIR EN PERSPECTIVA COMPARADA EL PERFIL SOCIAL DE LOS PARTIDOS?}

Como se ha mostrado en la primera parte del artículo, con los datos del Manifesto Project es posible analizar tendencias e identificar casos desviados tanto a nivel macro como meso acerca del apoyo programático al gasto social. Sin embargo, se precisan herramientas adicionales para examinar de forma más completa la diferenciación de la oferta en este ámbito y mapear su evolución. Por eso, se ha innovado en la creación de datos comparables que permiten trazar perfiles sociales y antisociales de los partidos.

Para la producción de estos datos, en lo que se refiere al perfil social, se tienen en cuenta dos criterios particularmente relevantes: los beneficiarios, a quienes se dirige la oferta electoral, y los programas de gasto. Cada uno de estos criterios permite definir un perfil social complementario: el perfil social 
de acuerdo con los beneficiarios enfatizados — «perfil social_beneficiarios»—, y el perfil social relativo a los programas de gasto priorizados (sanidad, pensiones, educación, servicios sociales, vivienda, o empleo) — «perfil social_programas»—.

Los nuevos datos pueden obtenerse gracias al Manifesto Corpus (Merz et al., 2016), que es la provisión por parte del proyecto Manifesto, con carácter complementario a sus datos, no solo de los textos originales de los programas, sino también de los documentos de trabajo llamados versiones «anotadas», donde figuran las cuasi-frases con los códigos atribuidos. Esto facilita la recodificación de los textos, manteniendo como unidad de análisis la cuasi-frase o empleando palabras u otras alternativas.

El proceso que planteamos en este artículo para generar el «perfil social_ beneficiarios» de un partido es el siguiente:

a) Se seleccionan las unidades de análisis de la versión anotada de los programas dedicadas al gasto social (códigos 504, 505, 506, y 507).

b) Se identifican los destinatarios mencionados, haciendo, en castellano (para otras lenguas se precisan diccionarios de equivalentes), las siguientes búsquedas: NIÑ, INFAN, MENOR, ADOLESCEN, JUVEN, JOVEN, ADULT, MAYOR, ANCIAN, TERCERA EDAD, DESEMPLE, PARAD, PARO, LARGA DURACIÓN, JUBILA, DISCAPACI, DEPEND, FAMILIA, MADRE, MATERN, MUJER, EXTRANJER, INMIGRA, REFUGI, VULNERAB, EXCLU, DESFAVORECID, RECURSOS, NECESIDAD, NECESIT, POBRE.

c) Se elabora un Excel únicamente con las unidades de análisis del programa anotado donde aparezcan alguna o varias de las anteriores búsquedas.

d) Se revisa en cada unidad de análisis si la búsqueda se corresponde con alguno de los siguientes beneficiarios, descartando el resto de unidades de análisis:

— Grupos de edad: NIÑ, INFAN, MENOR, ADOLESCEN, JUVEN, JOVEN/ADULT/MAYOR, ANCIAN, TERCERA EDAD.

- Grupos laborales: DESEMPLE, PARAD, PARO/LARGA DURACIÓN/JUBILA.

Otros destinatarios de atención social:

— Dependientes: DISCAPACI, DEPEND.

- Familias: FAMILIA, MADRE, MATERN.

— Mujeres (excluyendo el rol de madres): MUJER. 
— Personas de origen extranjero, inmigrantes, refugiadas: EXTRANJER, INMIGRA, REFUGI.

— Personas "que necesitan»" ${ }^{1}$ ayuda: VULNERAB, EXCLU, DESFAVORECID, RECURSOS, NECESIDAD, NECESIT.

- Pobres: POBRE.

e) Se calcula la proporción de cada una de las opciones de destinatarios (nińos y jóvenes, mayores, desempleados, desempleados de larga duración, dependientes, familias, mujeres, inmigrantes, necesitados y pobres) sobre el total de beneficiarios mencionados. Cuando en una unidad de análisis se hace referencia a varios destinatarios, se cuenta individualmente cada uno de ellos.

En el epígrafe siguiente se ejemplifica el resultado de la aplicación de este proceso a los programas del PP, PSOE, Podemos y Ciudadanos para las elecciones generales de 2016.

Por su parte, el procedimiento de elaboración del «perfil social_programas» es el siguiente:

a) Se seleccionan las unidades de análisis de la versión anotada de los programas dedicadas al gasto social (códigos 504, 505, 506, y 507).

b) Se identifican los programas de gasto mencionados, haciendo, en castellano, las siguientes búsquedas: SANI, SALUD/PENSION/EDUCA/ SERVICIOS SOCIALES/VIVIENDA/EMPLEO, LABORAL.

c) Se elabora un Excel únicamente con las unidades de análisis del programa anotado donde aparezca alguna o varias de las anteriores búsquedas.

d) Se revisa en cada unidad de análisis si estas búsquedas se corresponden con alguno de los siguientes programas, eliminando las unidades de análisis sobrantes:

- Sanidad: SANI, SALUD

- Pensiones: PENSION

1 Nótese que la categoría «personas que necesitan» («vulnerables», «excluidas», «desfavorecidas», «sin recursos», etc.) puede recoger posicionamientos a favor de la desuniversalidad de la protección social. En sentido más amplio, se trata de preferencias encubiertas favorables a una menor intervención pública en materia de bienestar. Pobreza se ha considerado una categoría distinta. 
- Educación: EDUCA

- Servicios sociales: SERVICIOS SOCIALES

- Vivienda: VIVIENDA

- Empleo: EMPLEO, LABORAL.

e) Se calcula la proporción de cada uno de estos programas sobre el total de los programas de gasto mencionados. Cuando en una unidad de análisis se hace referencia a varios programas, se cuenta individualmente cada uno de ellos.

Más adelante se muestra el resultado de la aplicación de este procedimiento en las elecciones generales españolas de 2016.

Finalmente, en este epígrafe indicamos cómo medir el perfil antisocial de los partidos.

Las posiciones explícitamente favorables a los recortes en políticas sociales pueden estar fundamentadas en argumentos morales y/o económicos. La proporción de estas dos clases de razones marca una diferencia significativa en la oferta electoral de un partido, que puede condicionar la definición de los programas de gasto, pero no agota la variación relevante. Volviendo al modelo de Hirschman (1991), un partido puede rechazar el EdB por su inutilidad o por su peligrosidad, mientras otro puede estar más preocupado por su perversidad moral. Estos tres conceptos resultan todavía más reveladores de la idea de intervención pública en materia de bienestar preferida por los partidos que la mera contraposición de argumentos morales y económicos.

El proceso de definición del perfil antisocial de un partido es el siguiente:

a) Se seleccionan las unidades de análisis de la versión «anotada» de los programas que capturan posicionamientos a favor de los recortes sociales (códigos 505 y 507).

b) En cada una de estas unidades se evalúa si el argumento se enmarca en la noción de peligrosidad, inutilidad, o perversidad, de acuerdo con lo detallado más abajo.

c) Se calcula la proporción de cada una de esas tres ideas sobre el total de unidades de análisis (códigos 505 y 507).

Para decidir si el razonamiento crítico desarrollado en una unidad de análisis (códigos 505 y 507) versa sobre las ideas de «peligrosidad», «inutilidad» o «perversidad» se tiene en cuenta lo siguiente: el EdB, como se ha desarrollado ya con extensión en este texto, se considera peligroso porque lastra el crecimiento económico y pone en riesgo la creación de riqueza y bienestar. Se encuadran, por tanto, en este concepto general de peligrosidad: apelaciones a la eficiencia y, en general, argumentos económicos de nivel macro, como referencias a la racionalización del gasto o a la evaluación de los programas. Ejemplos: 
— «Generalizar la prescripción y dispensa de medicamentos en dosis individual (dentro de blíster) en las farmacias comunitarias para episodios agudos» (Centro Socialdemócrata-Partido Popular, CDS-PP, Portugal 2011) $)^{2}$.

— «Someteremos los fondos para el empleo a una auditoría financiera externa» (Partido Popular Social Cristiano, CSV/PCS, Luxemburgo 2013).

$\mathrm{El} \mathrm{EdB}$ es inútil porque el sector privado gestiona mejor servicios y derechos. En esta categoría se ubican posiciones favorables a las formas mixtas de provisión de bienestar e incluso a la dualización de la red de protección social, siempre que el razonamiento sea económico y no moral. Bajo esta idea general de inutilidad podría defenderse a empresas y ONGs como mejores gestoras de dinero público, sin que ello entrañe una preferencia por la reducción del gasto público. También cabría apoyar la incorporación o la extensión de la participación de provisores de atención social no pertenecientes al sector público en tanto que competidores del Estado, o substitutivos de la intervención pública, con lo que sí se estaría planteando una disminución del gasto público. Ejemplos:

— «Defendemos la transferencia de equipamientos sociales que gestiona directamente el Estado central a las entidades del sector solidario que integran la red social local» (CDS-PP, Portugal 2011).

— «Creación de estructuras de apoyo a pequeñas y medianas entidades de economía social para reducir su dependencia de las subvenciones estatales» (CDS-PP, Portugal 2011).

- Continuaremos apoyando las escuelas privadas y las escuelas internacionales (CSV/PCS, Luxemburgo 2013).

Para terminar, el EdB es perverso porque aumenta el riesgo moral de dependencia, fraude y corrupción de individuos e instituciones. Incluso, se le podría responsabilizar de tener efectos igual de perversos sobre la sociedad civil al ocupar espacio y funciones tradicionalmente asignados a las familias e interviniendo y estatalizando el tejido comunitario. Bajo esta categoría general de perversidad se reúnen afirmaciones en contra de la asistencia social

2 Las referencias se extraen de la versión «anotada» de los programas, por lo que no se indica la página en el texto original. Estas versiones «anotadas» pueden consultarse en el sitio en Internet del proyecto Manifesto: https://manifesto-project.wzb.eu/. Las traducciones de las cuasi-frases empleadas como ejemplos han sido realizadas por los autores. 
basadas en argumentos morales, posiciones contrarias a las prestaciones no contributivas, menciones al equilibrio entre derechos y deberes o a la responsabilidad individual sobre las propias condiciones de vida, referencias a la activación o a incentivos a la inserción laboral, y apelaciones a la familia o a voluntarios como alternativa a la intervención pública fundamentadas en criterios morales (si el razonamiento fuese económico, se ubicaría en la idea de inutilidad del EdB y no en la de perversidad). Ejemplos:

— «Deseamos que la protección social sea fundada sobre los derechos y los deberes de cada uno, y que pasemos de una lógica de asistencia a una lógica de responsabilidad» (Unión por un Movimiento Popular, UMP, Francia 2012).

— «Suspender las asignaciones familiares para las familias que no desempeñan su papel contra el absentismo escolar» (UMP, Francia 2012).

— «Todas las prestaciones sociales comportan un riesgo moral cuando su atribución es más atractiva que la inclusión o regreso al mercado laboral» (CDS-PP, Portugal 2011).

- «La obtención de ayudas al nacimiento estará ligada a la participación en cursos específicos» (CSV/PCS, Luxemburgo 2013).

- «Favoreceremos las iniciativas privadas que pretenden desarrollar modos de vida solidaria en el seno de las familias sea para los estudiantes extranjeros o más todavía las personas mayores» (CSV/PCS, Luxemburgo 2013).

\section{LOS PERFILES SOCIALES DE LOS PRINCIPALES PARTIDOS ESPAÑOLES DE ÁMBITO ESTATAL}

Como ya se ha destacado, España, junto con Alemania, Austria, Dinamarca, Portugal y Suecia, es uno de los países de la UE-15 donde aumentó el apoyo parlamentario a la expansión de los programas de gasto en la Gran Crisis en contra de la tendencia general. Aunque el énfasis en los recortes sociales es residual a nivel macro en los quince Estados, constituye también, después de Grecia, el país donde se han formulado menos promesas de recortes.

¿Esto implica que en España no pueda hablarse de diversidad programática en materia de políticas de bienestar? En absoluto, como hemos podido medir con la herramienta que acabamos de presentar, e incluso también en menor medida con los propios datos del proyecto Manifesto. Empleando únicamente los datos de la base principal de este proyecto se observan algunas diferencias entre los principales partidos. En primer lugar, aunque en el plano del discurso programático el PP dista de ser un partido contrario al aumento 
de la financiación de las políticas sociales, como se refleja en el gráfico 5, su posición se ha mantenido en el tiempo a una distancia de 3-4 puntos por debajo de la del PSOE, que ha prestado sistemáticamente más atención a estas políticas en sus programas.

\section{Gráfico 5. Posición sobre la extensión del gasto social del PP, PSOE, Podemos y Ciudadanos}

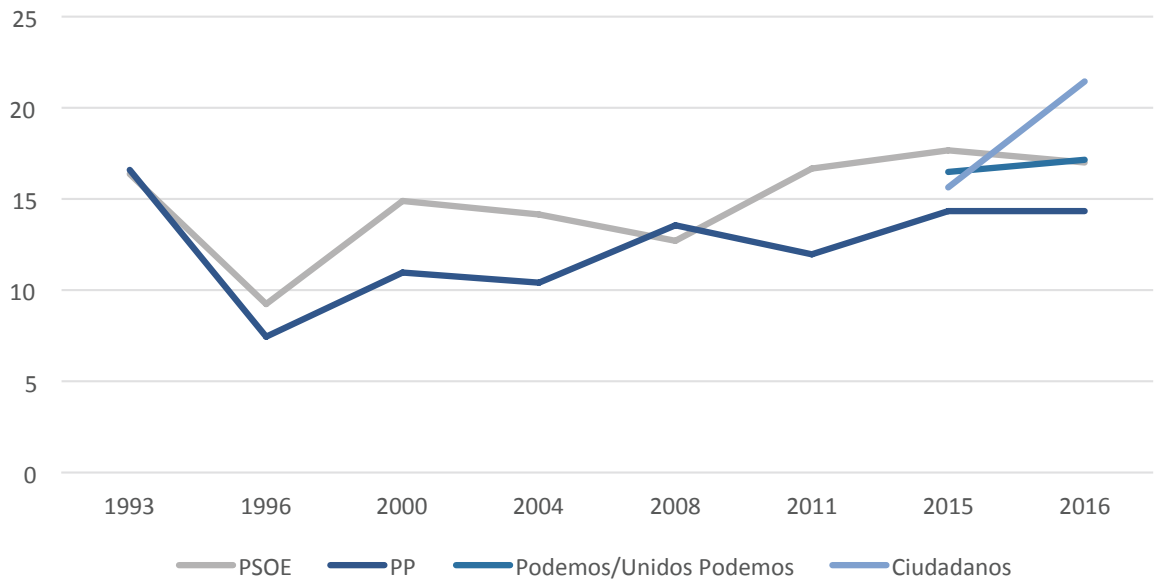

Fuente: elaboración propia con datos del Manifesto Project. Versión 2017b.

La única excepción se produce en las elecciones de 2008, justo al inicio de la Gran Recesión, cuando paradójicamente el PSOE redujo en 1,44 su preferencia por la expansión del gasto social y, en cambio, el PP la aumentó 3,14 puntos, alcanzando una posición de 13,57 , coincidente con su media del período 2008-2016; esta media en los comicios celebrados entre 1996 y 2004 fue 9,61. La condición de partido de gobierno a nivel estatal, primero, y la Gran Crisis, después, fueron «socializando» el discurso del PP, sin que el PSOE, que en paralelo fue reforzando su defensa de los programas de gasto, salvo en 2008, dejase de ser un partido más favorable que el PP al aumento de los recursos del EdB.

Podemos se situó en el escenario de competición en 2015 con una preferencia a favor de la expansión del gasto social de 16,48, lo que significa 1,2 puntos por debajo del PSOE, 2,13 por encima del PP y 0,84 de Ciudadanos. Sobre Ciudadanos es preciso subrayar cómo este partido modificó significativamente su oferta para hacerla más favorable a los programas de gasto $(+5,81)$ en las elecciones de 2016 respecto a las de 2015. De hecho, en 2016, fue el partido más 
comprometido con la financiación de las políticas de bienestar $(21,45)$, no solo por encima del PP $(14,35)$, como ya había ocurrido en 2015, sino también de Unidos Podemos $(17,16)$ y del PSOE (17). Dado el espacio reservado en los programas y los intervalos de variación de la oferta sobre la expansión del gasto social, podemos afirmar que en España esta es una decisión relevante en la estrategia electoral de los partidos, resultando además informativa la comparativa entre los programas presentados en 2015 y en 2016.

Si ponemos el foco únicamente en los posicionamientos favorables a los recortes en los partidos españoles de ámbito estatal con representación parlamentaria desde 1996, solo se registran seis observaciones donde aparece alguna mención favorable a la reducción del gasto social. Estas son: PP en 1996, 2000, 2015 y 2016; UPyD en 2011, y Ciudadanos en 2015.

La frecuencia de las referencias antisociales se muestra en el gráfico 6 . Como puede comprobarse, es siempre muy baja, resultando las puntuaciones más altas las del PP en $2000(0,68)$ y 2015/2016 $(0,46)$.

Gráfico 6. Énfasis en los recortes sociales del PP, UPyD y Ciudadanos

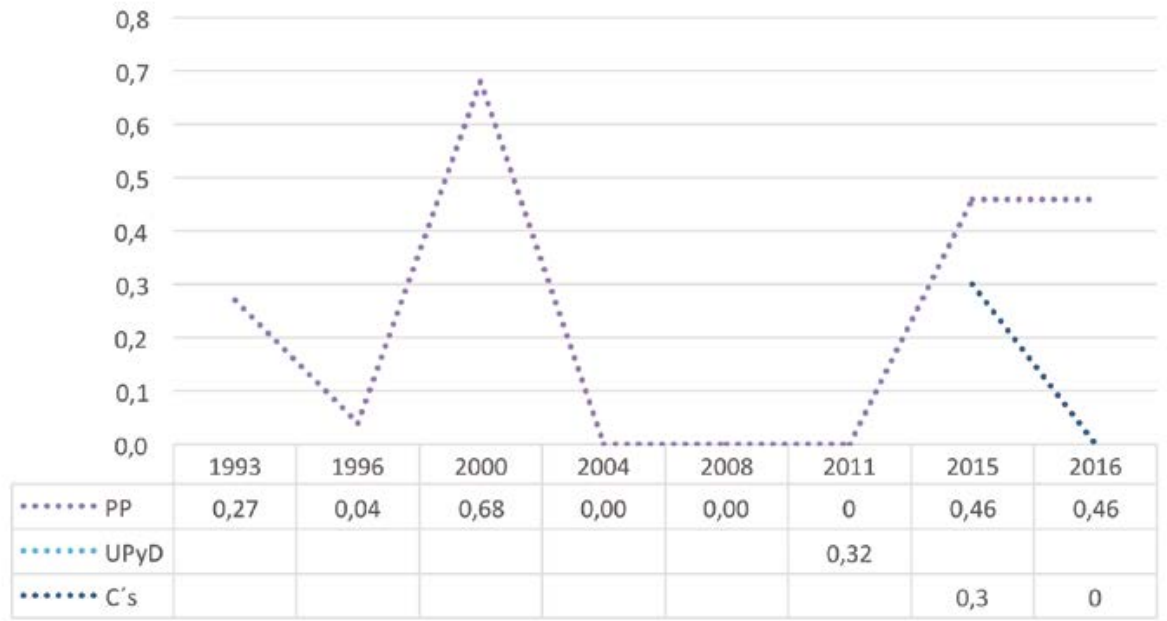

Fuente: elaboración propia con datos del Manifesto Project. Versión 2017b.

Hasta aquí lo que podría decirse sobre la diferenciación de la oferta electoral en materia de bienestar en España trabajando únicamente con los datos de la base principal del Manifesto. Aplicando el desarrollo metodológico presentado en este trabajo, es posible completar el análisis como explicamos a continuación. 
Definimos los «perfiles sociales_beneficiarios» y los «perfiles sociales_ programas" del PP, PSOE, Podemos y Ciudadanos en 2016, y el "perfil antisocial» de los partidos espańoles de ámbito estatal que desde 1996 han hecho alguna mención a los recortes en sus programas: PP, UPyD y Ciudadanos ${ }^{3}$.

Los "perfiles sociales_beneficiarios» se recogen en la tabla 2. Se puede valorar en qué medida los partidos dirigen su oferta social a los distintos grupos de edad. El primer dato destacable es que en 2016 el PSOE —ni Podemos $(4,86)$ ni Ciudadanos $(4,47)$ — es el partido que presta más atención a los niños y a los jóvenes $(8,42)$, con mucha distancia respecto al segundo en hacerlo, el PP $(4,95)$. Esto prueba que el discurso mediático que sugiere que los partidos tradicionales no dirigen sus mensajes a los jóvenes no tiene base empírica en el plano de la oferta programática en estos comicios en España.

Tabla 2. «Perfil social_beneficiarios» del PP, PSOE, Podemos y Ciudadanos (elecciones generales de 2016)

\begin{tabular}{lllll}
\hline \multicolumn{1}{c}{ Beneficiarios } & PP & PSOE & Podemos & Ciudadanos \\
\hline Nińos, adolescentes y jóvenes & 4,95 & 8,42 & 4,86 & 4,47 \\
\hline Mayores & 3,85 & 1,68 & 0,69 & 0 \\
\hline Discapacitados/dependientes & 4,95 & 4,09 & 6,6 & 6,15 \\
\hline Familias/maternidad & 15,11 & 9,51 & 14,93 & 10,61 \\
\hline Mujeres & 1,1 & 2,29 & 2,43 & 1,12 \\
\hline Vulnerables & 12,1 & 4,93 & 6,6 & 1,68 \\
\hline Pobres & 1,92 & 3,01 & 1,74 & 3,91 \\
\hline
\end{tabular}

* La puntuación de cada partido se expresa como porcentaje de unidades de análisis en relación con el total de unidades de análisis del programa dedicadas al gasto social. Estas fueron: 364 (PP), 831 (PSOE), 288 (Podemos) y 179 (Ciudadanos), respectivamente.

Fuente: elaboración propia con datos del Manifesto Project, versión 2017b.

3 En 2004, aparece algún posicionamiento antisocial en el programa del PSOE, y su puntuación es 0,02. No se contempla por su irrelevancia y porque el Manifesto Project no ofrece todavía este programa "anotado» en Excel. Los perfiles sociales y antisociales de los partidos españoles se definen desde 1996 debido a que esta es la primera elección para la que se dispone de todos los programas «anotados» necesarios. 
Con relación a los mayores como destinatarios de políticas sociales, mientras Podemos $(0,69)$ y Ciudadanos $(0)$ simplemente les prestan poca o nula atención, el PSOE $(1,68)$ y, en mayor medida, el PP $(3,85)$ sí elaboran propuestas específicas para ellos, aunque en menor (PP -1,1 punto) o mucha menor medida (PSOE -6,74) que para los jóvenes 4 .

Estos datos permiten sostener que no se trata tanto de que los nuevos partidos amplíen la oferta electoral de servicios de bienestar para las generaciones más jóvenes, sino que tienen menos en cuenta a las personas mayores.

Seguramente esta estrategia parta de la asunción de que los mayores presentan un comportamiento electoral menos volátil o más apegado a los partidos que han votado regularmente a lo largo de su vida adulta; por tanto, los nuevos partidos tienen pocas expectativas de que los votantes mayores vayan a confiar en ellos en grandes números y no aprecian la necesidad de incluir apartados programáticos específicamente pensados para ellos. Si en el futuro se llegase a consolidar la percepción de que existe una guerra entre generaciones en España por los recursos de las políticas de bienestar, sería razonable preguntarse si no fueron las estrategias electorales de los nuevos partidos Ciudadanos y Podemos las que contribuyeron decisivamente a introducirla en la agenda política.

En cambio, el "perfil social_beneficiarios» retrata en las mismas elecciones de 2016 a Podemos $(6,6)$ y Ciudadanos $(6,15)$ más preocupados por la atención a la dependencia que el PP $(4,95)$ y el PSOE $(4,09)$. En su programa de estos últimos comicios, más social que el de 2015, Ciudadanos fue el partido que puso más énfasis en la pobreza $(3,91)$, casi un punto más que el PSOE $(3,01)$. Mientras, ni Podemos $(1,74)$ ni el PP $(1,92)$ dieron prioridad a las personas pobres. Los mensajes dirigidos a las mujeres (vinculados a los programas de gasto) fueron escasos, pero encontraron cierta acogida en el PSOE y en Podemos.

Atención aparte merecen las propuestas dirigidas a las «personas que más lo necesitan». Todos estos partidos emplearon en sus programas las coletillas «personas vulnerables», «excluidas», «sin recursos», etc., pero en 2016 el PP hizo un discurso especialmente cargado de estas referencias $(12,1)$. Algunas de estas menciones fueron introducidas con intención de enfatizar el apoyo a estos destinatarios, pero otras en realidad encubren de manera más o menos

4 Estos resultados son consistentes con lo obtenidos por Marí-Klose (2012: 73) en su análisis de contenido de los programas del PSOE entre 1982 y 1996. En las primeras ofertas socialistas también se prestaba «bastante menos atención» a las personas mayores que a los jóvenes. 
evidente el deseo de extender los recortes sociales por la vía de expulsar beneficiarios convirtiendo servicios universales en selectivos.

Los «perfiles sociales_programas», por su parte, se reflejan en los gráfi$\cos 7$ a 10. Si bien muestran menos variación entre los cuatro partidos en comparación con los "perfiles sociales_beneficiarios", presentan dos diferencias y un rasgo común significativos. La primera disimilitud es que Ciudadanos es el único partido que prioriza la educación sobre la sanidad, dato que refuerza su inclinación a la falta de atención a las personas de más edad como destinatarias de gasto social. La segunda diferencia es que Podemos y el PSOE se preocupan más por la vivienda social que el PP y Ciudadanos. El elemento común relevante es que ni el PP ni el PSOE enfatizan en su oferta electoral las pensiones frente a otros programas de gasto, como la educación o el empleo.

Gráficos 7 a 10. «Perfil social_programas»del PP, PSOE, Podemos y Ciudadanos en 2016

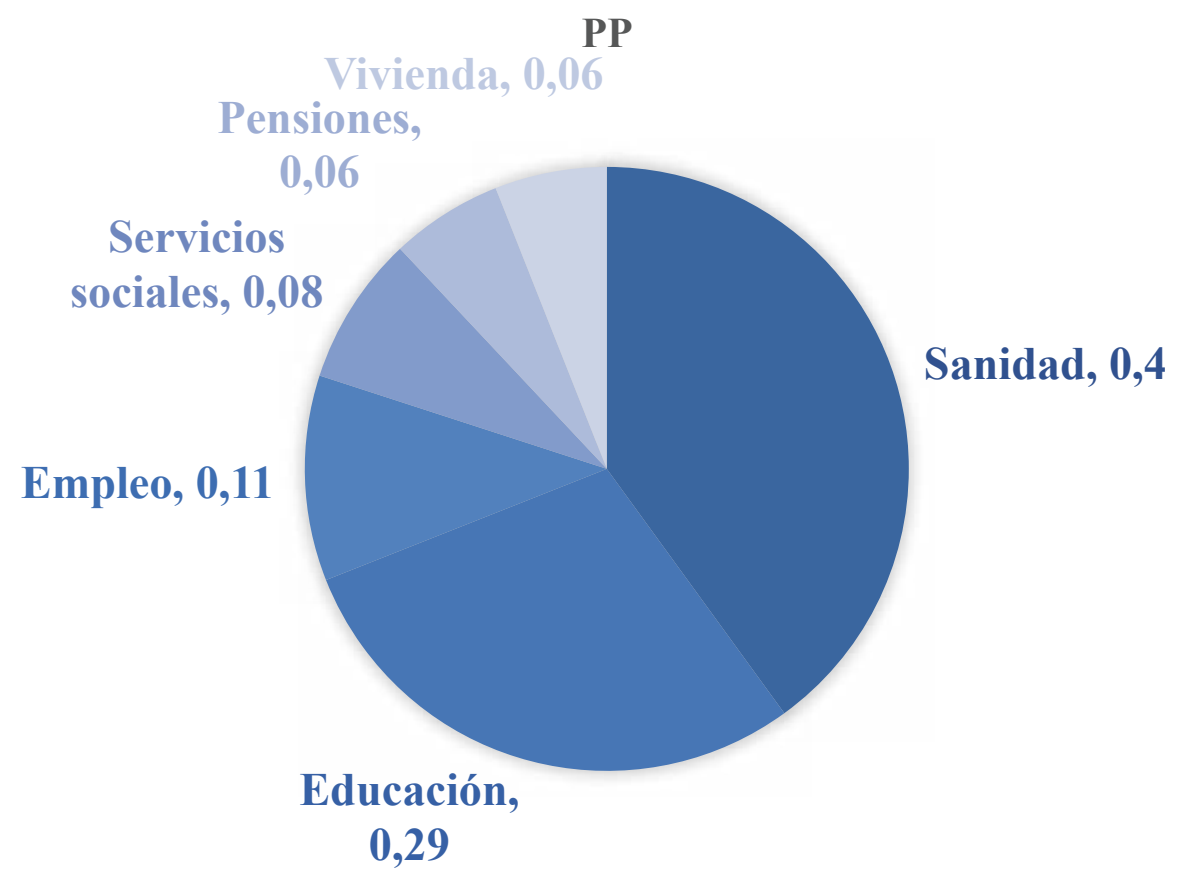



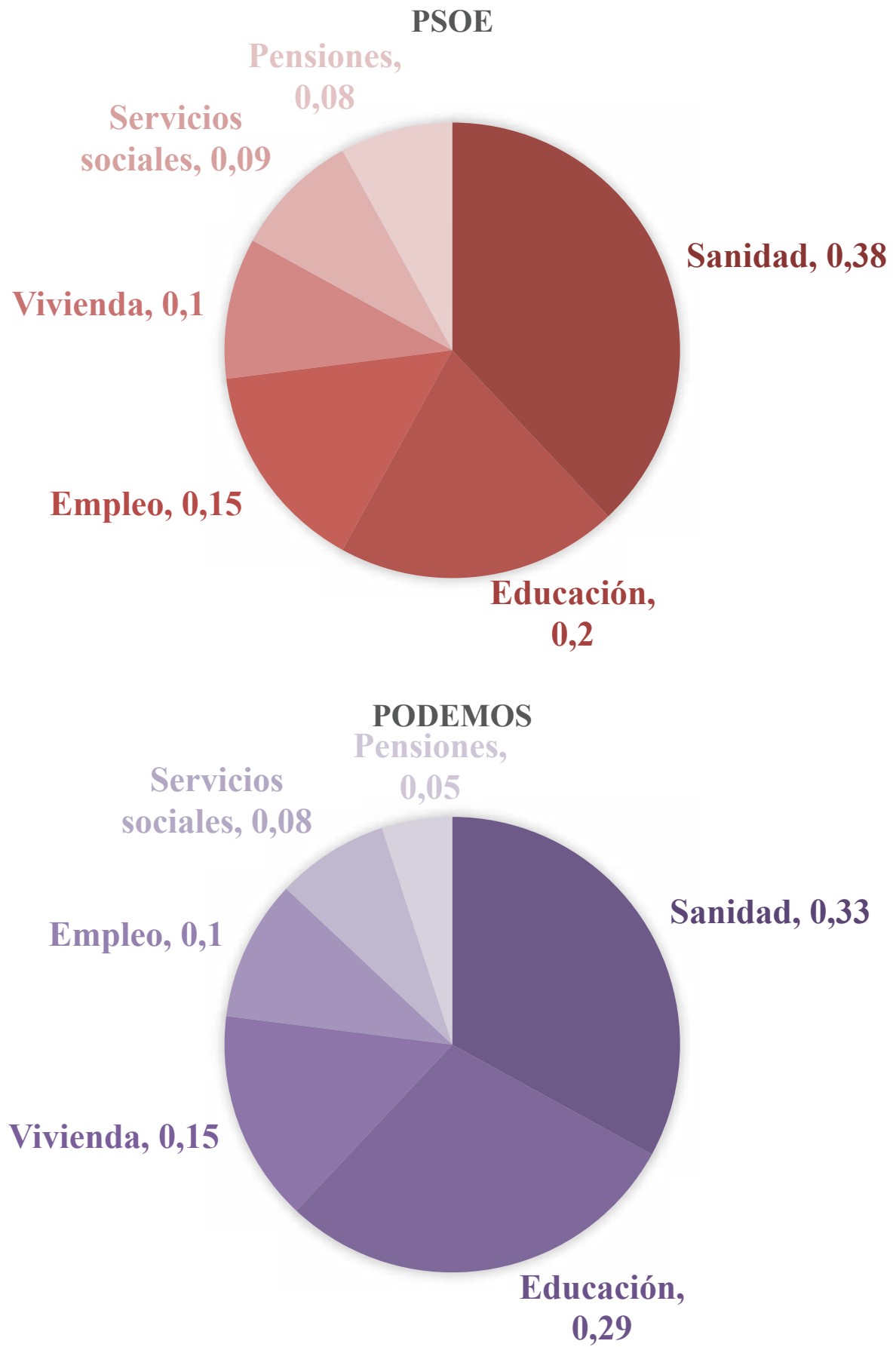


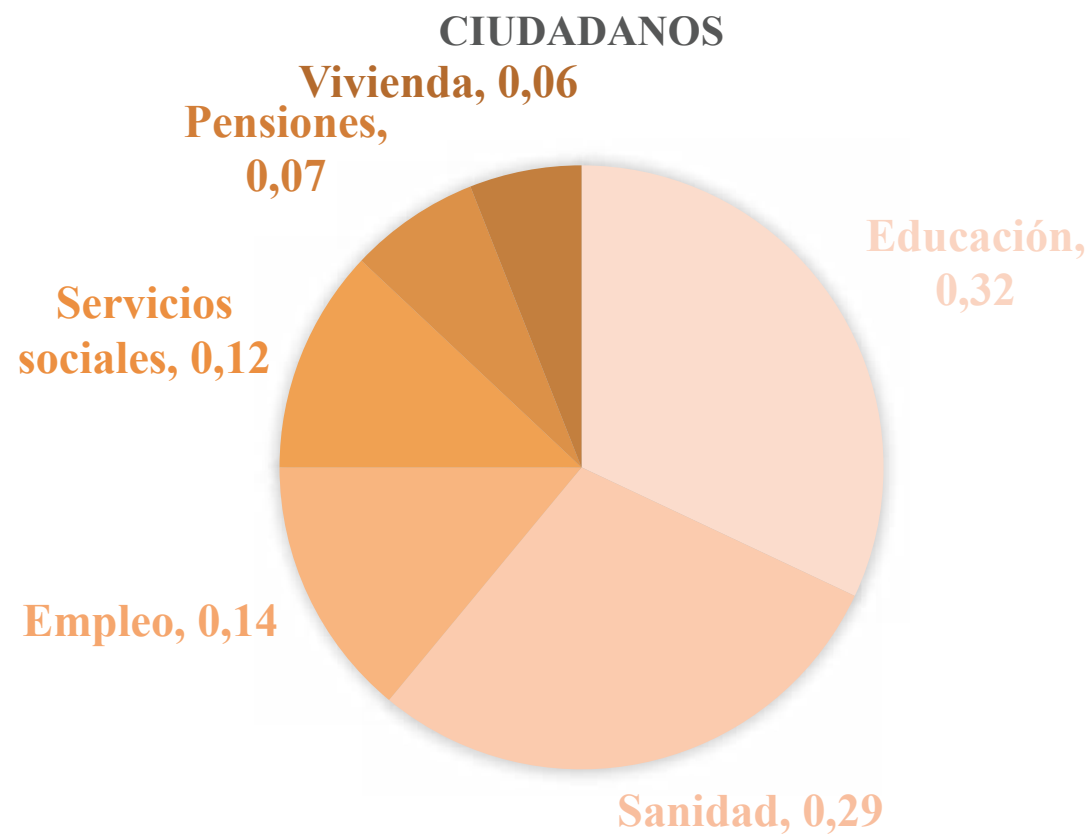

* Las puntuaciones de cada programa (sanidad, educación, vivienda, etc.) representan la proporción de sus menciones sobre el total de referencias a los programas de gasto contenidas en el texto programático.

Fuente: elaboración propia.

Finalmente, la tabla 3 contiene los «perfiles antisociales» del PP en 1996, 2000, 2015 y 2016, UPyD en 2011, y Ciudadanos en 2015. El PP ha ido modificando su razonamiento favorable a los recortes. Si en 1996 se limitaba a la idea de inutilidad del EdB, en 2000 equilibró sus críticas entre inutilidad y perversidad, y en 2015 y 2016 pasó a enfatizar la noción de perversidad. Esto quiere decir que el PP se volvió más conservador e incluso neoliberal en estos temas. Sin embargo, las críticas de Ciudadanos no se fundamentaron en razones morales, sino solo económicas, sobre todo encuadradas en la noción de inutilidad del EdB. Del mismo modo, UPyD en 2011 había empleado para oponerse al gasto social únicamente razones económicas en torno a la idea de peligrosidad. 
Tabla 3. Perfil antisocial de Ciudadanos, PP y UPyD

\begin{tabular}{lccc}
\hline \multicolumn{1}{c}{ El EdB es... } & perverso & peligroso & inútil \\
\hline PP 1996 & 0 & 0 & 1 \\
\hline PP 2000 & 0,5 & 0 & 0,5 \\
\hline PP 2015 & 0,82 & 0,09 & 0,09 \\
\hline PP 2016 & 0,82 & 0,09 & 0,09 \\
\hline UPyD 2011 & 0 & 1 & 0 \\
\hline Ciudadanos 2015 & 0 & 0,21 & 0,79 \\
\hline
\end{tabular}

* Estas puntuaciones representan la proporción de los indicadores correspondientes a los conceptos de perversidad, peligrosidad e inutilidad del Estado de bienestar sobre el total de unidades de análisis de los programas con referencias favorables a los recortes sociales (categorías 505 y 507 del esquema de clasificación estándar del Manifesto Project).

Fuente: elaboración propia.

\section{CONCLUSIONES}

Este artículo presenta tres procedimientos para la definición de los perfiles sociales y antisociales de los partidos políticos en perspectiva comparada. A partir de estos procesos se generan nuevos datos que van más allá de los ofrecidos por el proyecto Manifesto sobre la extensión o limitación del EdB. Han podido construirse gracias al Manifesto Corpus (Merz et al., 2016), que ofrece los programas «anotados» en formato Excel con las unidades de análisis y la identificación del código asignado por el Manifesto Project.

Asimismo, se ha comparado la evolución de las preferencias programáticas respecto a la financiación de las políticas de bienestar en la UE-15 y se ha constatado que el ciclo de la oferta de los partidos en materia de gasto social presenta ciertas diferencias en Espańa con respeto a las tendencias agregadas europeas. La oferta de recortes sociales tiende a aumentar en este país tras las crisis económicas y con los inicios de la recuperación, mientras que la media de la UE-15 se ajusta casi perfectamente al propio ciclo de recesión/crecimiento de la economía: aumenta la oferta programática de recortes sociales durante las recesiones y se contrae en los momentos de expansión.

Además, solo el PP en 1996, 2000, 2015 y 2016, UPyD en 2011, y Ciudadanos en 2015 han incorporado a sus estrategias electorales referencias 
favorables a los recortes en los programas de gasto, aunque cuantitativamente poco relevantes.

Por tanto, en España la oferta sobre los programas de gasto se construye sobre el compromiso de mantener inalterable el grueso de las políticas sociales o de proteger el núcleo duro del EdB. Las propuestas de transformación se presentan dentro de un marco de mantenimiento y continuidad, como un cambio marginal que no afecta a los derechos y programas más consolidados. Ninguno de los grandes partidos españoles de ámbito estatal considera el EdB peligroso, perverso o inútil; y todos, incluso los más conservadores, administran y miden con cuidado sus discursos críticos en materia de políticas de bienestar.

Esto no quiere decir que los partidos presenten la misma oferta electoral sobre el EdB; de hecho, se registren diferencias y matices muy significativos. Salvo en 2008, el PSOE siempre ha formulado más propuestas para la expansión de la financiación de las políticas de bienestar que el PP. La izquierda ha apostado por empujar en sus programas el crecimiento del gasto, mientras que la derecha ha tendido más bien a consolidarlo asumiéndolo como propio.

Entre los partidos en alguna medida partidarios de los recortes (Ciudadanos, PP y UPyD) también se registran diferencias interesantes. El PP en 2000 y en mayor medida en 2015 y 2016 es el único que asume la noción de perversidad del EdB y muestra preferencia por los argumentos de riesgo moral, abuso y fraude al sistema, recompensa de la dependencia y castigo a la iniciativa y la responsabilidad individuales. Ni UPyD ni Ciudadanos han empleado argumentos morales para apostar por la reducción del gasto social. Ambos han preferido ceñir su discurso crítico a la inutilidad o a la peligrosidad del EdB, invocando prioritariamente problemas de eficacia o de eficiencia en la gestión. UPyD construye su oposición de acuerdo con la idea de peligrosidad del EdB, por cuanto supone poner en riesgo otros avances o logros conseguidos y amenaza la sostenibilidad del crecimiento económico y la creación de riqueza. Ciudadanos prefiere el argumento de la inutilidad de algunas medidas para asegurar los objetivos de igualdad y de redistribución de oportunidades que dice promover.

Los nuevos perfiles sociales «beneficiarios» y "programas» permiten desmentir algunas creencias presentes en el debate público acerca de la preferencia por las personas mayores como destinatarios de atención social en la oferta del PP y del PSOE. Los datos indican que estos partidos no enfatizaron, por ejemplo, las pensiones sobre otras políticas de bienestar, como la educación o el empleo. Bien al contrario, se ha acreditado cómo sobre todo el PSOE prioriza de manera regular a los niños y a los jóvenes frente a los mayores. 
Paradójicamente, se ha constatado que los nuevos partidos no han elaborado de manera sistemática propuestas dirigidas a los grupos sociales de más edad. De hecho, Ciudadanos es el único de los principales partidos españoles de ámbito estatal que pone el foco en la financiación de políticas en principio más beneficiosas para las generaciones más jóvenes, como la educación, en lugar de en otros programas de gasto que afectan en mayor medida a las personas mayores, como la sanidad.

Iniciado este camino de la investigación comparada, que debe ampliarse con más datos sobre los perfiles sociales de los partidos parlamentarios de la UE-15, puede que se acabe llegando a la sorprendente, pero bastante razonable conclusión, de que puestos a asignar responsabilidades en una supuesta batalla entre generaciones por el reparto del presupuesto habría que empezar a buscarla en las estrategias de algunos nuevos partidos más que en una defensa cerrada de los intereses de las personas mayores como grupo por parte de los viejos.

\section{Bibliografía}

Alonso, S., Volkens, A. y Gómez, B. (2012). Análisis de contenido de textos politicos. Un enfoque cuantitativo. Madrid: Centro de Investigaciones Sociológicas.

Ares, C. (2018). Envejecimiento y política: un debate politológico. Revista de Estudios Políticos, 179.

— y Volkens, A. (2017a). ¿Por qué y cómo se está extendiendo el Manifesto Project a América Latina? Revista Española de Ciencia Política, 43, 115-135. Disponible en: https:// doi.org/10.21308/recp.43.05.

- (2017b). Representación, estructura de la competencia e ideología de los partidos políticos: el empleo de los indicadores de MARPOR en América Latina. Revista Latinoamericana de Política Comparada, 12, 9-28.

Blyth, M. (2014). Austeridad. Historia de una idea peligrosa. Barcelona: Crítica.

Boix C. (1996). Partidos políticos, crecimiento e igualdad. Madrid: Alianza.

Busemeyer, M. R., Goerres, A. y Weschle, S. (2008). Demands for Redistributive Policies in an Era of Demographic Aging: The Rival Pressures from Age and Class in 15 OECD Countries. Discussion Paper DP08, 3. Max Planck Institute for the Study of Societies (MPIFG).

Clarke, J. y Newman, J. (1999). The Managerial State. London: Sage.

Cutler, T. y Waine, B. (1994). Managing the Welfare State. The politics of public sector management. Oxford: Berg.

Dunleavy, P. (1991). Democracy, Bureaucracy and Public Choice. London: Polity Press.

Esping-Andersen, G. (1990). The Three Worlds of Welfare Capitalism. Cambridge: Polity Press; Princeton: Princeton University Press.

- y Palier, B. (2010). Los tres grandes retos del estado del bienestar. Barcelona: Ariel.

Goerres, A. (2007). Can We Reform the Welfare State in Times of "Grey" Majorities? The Myth of an Electoral Opposition between Younger and Older Voters in Germany. Working Paper 07-05. Max Planck Institute for the Study of Societies. 
- (2009). The Political Participation of Older People in Europe. The Greying of our Democracies. Basingstoke: Palgrave. Disponible en: https://doi.org/10.1057/9780230233959.

Hirschman, A. O. (1991). The Rethoric of Reaction. Cambridge: Harvard University Press.

Lane, J. E. y Ersson, S. (1999). Politics and Society in Western Europe. London: Sage. Disponible en: https://doi.org/10.4135/9781446279342.

Losada, A. (2013). Piratas de lo público. Barcelona: Deusto.

Lynch, J. (2015). Age Politics and Pension Systems Development and Reform. En C. Torp (ed.). Challenges of Aging. Pensions, Retirementand Generational Justice (pp. 49-60). Basingstoke: Palgrave.

Marí-Klose, P. (2012). Prioridades poco prioritarias. Jóvenes en la agenda gubernamental en España (1982-1996). Revista Española de Investigaciones Sociológicas, 140, 69-88.

Merz, N., Regel, S. y Lewandowski, J. (2016). The Manifesto Corpus: A newresource for research on political parties and quantitative text analysis. Research and Politics, 2, 1-8. Disponible en: https://doi.org/10.1177/2053168016643346.

Moreno, L. (2013). La Europa antisocial. Barcelona: Península.

Niskanen, W. (1971). Bureaucracy and Representative Government. Atherton: Aldine.

Nozick, R. (1974). Anarchy, State and Utopía. New York: Basic Books.

O'Connor, J. (1973). The Fiscal Crisis of the State. New York: St.James. Disponible en: https:// doi.org/10.1007/978-1-349-06273-7.

— (1984). Acumulation Crisis. New York: St.James.

Offe, C. (1985). Disorganiced Capitalism. London: Hutchinson.

Pierson, C. (1991). Beyond the Welfare State? Cambridge: Polity Press.

Pinch, S. (1997). Worlds of Welfare. Understanding the Changing Geographies of Social Welfare Provision. Londres; New York: Routledge.

Scharpf, F. (1991). Crisis and Choice in European Social Democracy. Ithaca; New York: Cornell University Press.

- (1999a). Governing in Europe, Effective and Democratic? Oxford: Oxford University Press. Disponible en: https://doi.org/10.1093/acprof:oso/9780198295457.001.0001.

- (1999b). Socialdemocracia y crisis económica en Europa. Valencia: Edicions Alfons el Magnànim.

Schulz, J. H. y Binstock, R. H. (2006). Aging Nations: The Economics and Politics of Growing Older in America. Westport: Praeger.

Volkens, A., Ares, C., Bratanova, R. y Kaftan, L. (2015). Scope, Range, and Extent of Manifesto Project Data Usage: A Survey of Publications in Eight High-Impact Journals. Handbook for Data Users and Coders. Versión 1. Disonible en: https://bit.ly/2Wh99Wk.

— , Bara, J., Budge, I., McDonald, M. y Klingemann, H.D. (ed.) (2013). Mapping Policy Preferences from Texts III. Statistical Solutions for Manifesto Analysts. Oxford: Oxford University Press. Disponible en: https://doi.org/10.1093/acprof:oso/9780199640041.001.0001.

— , Lehmann, P., Matthieß, T., Merz, N., Regel, S. y Weßels, B. (2017). The Manifesto Data Collection. Manifesto Project (MRG/CMP/MARPOR). Versión 2017b. Berlín: WZB. https://bit.ly/2HSc4Ba. 


\section{APÉNDICE DE TABLAS}

Tabla A1. Observaciones de preferencias sobre el gasto social en la UE-15 (1993-2017)

\begin{tabular}{llc}
\hline País & \multicolumn{1}{c}{ Elecciones } & Observaciones \\
\hline Alemania & $7(1994,1998,2002,2005,2009,2013$ y 2017) & 38 \\
\hline Austria & $7(1994,1995,1999,2002,2006,2008$ y 2013) & 36 \\
\hline Bélgica & $5(1995,1999,2003,2007$ y 2010) & 54 \\
\hline Dinamarca & $6(1994,1998,2001,2005,2007$ y 2011) & 52 \\
\hline Espańa & $8(1993,1996,2000,2004,2008,2011,2015$ y & 93 \\
\hline Finlandia & $5(1995,1999,2003,2007$ y 2011) & 41 \\
\hline Francia & $6(1993,1997,2002,2007,2012$ y 2017) & 63 \\
\hline Grecia & $10(1993,1996,2000,2004,2007,2009$, & \\
\hline mayo de 2012, junio de 2012, enero de 2015 y & 31 \\
\hline Irlanda & $5(1997,2002,2007,2011$ y 2016) & 71 \\
\hline Italia & $6(1994,1996,2001,2006,2008$ y 2013) & 27 \\
\hline Luxemburgo & $5(1994,1999,2004,2009$ y 2013) & 70 \\
\hline Países Bajos & $7(1994,1998,2002,2003,2006,2010$ y 2012) & 37 \\
\hline Portugal & $6(1995,1999,2002,2005,2009$ y 2011) & 44 \\
\hline Suecia & $6(1994,1998,2002,2006,2010,2014)$ & 32 \\
\hline Reino Unido & $5(1997,2001,2005,2010$ y 2015) & \\
\hline Número total & 94 & \\
\hline Comicios para los que se ofrecen datos en la base principal del Manifesto Project, versión $2017 \mathrm{~b}$. & \\
\hline
\end{tabular}


Tabla A2. Variación de la posición del Parlamento sobre la extensión del gasto social en la Gran Crisis (UE-15)

\begin{tabular}{lc}
\hline País & Variación de la posición del Parlamento nacional $^{*}$ \\
\hline Alemania & 5,81 \\
\hline Austria & 2,73 \\
\hline Bélgica & $-3,46$ \\
\hline Dinamarca & 5,16 \\
\hline Espańa & 1,21 \\
\hline Finlandia & $-6,05$ \\
\hline Francia & $-1,71$ \\
\hline Grecia & $-12,06$ \\
\hline Irlanda & $-7,38$ \\
\hline Italia & $-0,73$ \\
\hline Luxemburgo & $-5,27$ \\
\hline Países Bajos & $-6,16$ \\
\hline Portugal & 0,62 \\
\hline Suecia & 2,11 \\
\hline Reino Unido & $-5,46$
\end{tabular}

* En cada período legislativo se obtuvo la posición de cada partido con representación parlamentaria aplicando la fórmula $(504+506)-(505+507)$ y se ponderó por el número de escaños. Se mide el cambio en esta puntuación entre la elección inmediatamente anterior a 2008 y los comicios del período 2010-2013. Donde entre 2010 y 2013 se celebró más de una elección general, se calculó la posición del Parlamento resultante de cada una de ellas y se empleó la media.

Fuente: elaboración propia con datos del Manifesto Project, versión 2017b. 
Tabla A3. Posición sobre la extensión del gasto social en la UE-15 (2010-2013)

\begin{tabular}{lc}
\hline País & Posición sobre la extensión del gasto social \\
\hline Alemania & 11,17 \\
\hline Austria & 13,73 \\
\hline Bélgica & 9,44 \\
\hline Dinamarca & 16,85 \\
\hline Espańa & 13,23 \\
\hline Finlandia & 13,88 \\
\hline Francia & 17,72 \\
\hline Grecia & 9,56 \\
\hline Irlanda & 10,48 \\
\hline Italia & 10,55 \\
\hline Luxemburgo & 15,07 \\
\hline Países Bajos & 6,38 \\
\hline Portugal & 11,3 \\
\hline Suecia & 26,49 \\
\hline Reino Unido & 10,19 \\
\hline Media & 13,07
\end{tabular}

Fuente: elaboración propia con datos del Manifesto Project, versión 2017b. 
Tabla A4. Énfasis en los recortes sociales en la UE-15 (2010-2013)

\begin{tabular}{lc}
\hline País & Énfasis en los recortes en gasto social \\
\hline Alemania & 0,55 \\
\hline Austria & 1,54 \\
\hline Bélgica & 0,83 \\
\hline Dinamarca & 1,05 \\
\hline Espańa & 0,02 \\
\hline Finlandia & 1,06 \\
\hline Francia & 1,21 \\
\hline Grecia & 0 \\
\hline Irlanda & 1,58 \\
\hline Italia & 0,19 \\
\hline Luxemburgo & 2,16 \\
\hline Países Bajos & 2,13 \\
\hline Portugal & 2,33 \\
\hline Suecia & 0,19 \\
\hline Reino Unido & 0,44 \\
\hline Media & 1,02
\end{tabular}

Fuente: elaboración propia con datos del Manifesto Project, versión 2017b 